Research Article

\title{
New Aspects in the Mechanical Behavior of a Polycarbonate Found by an Experimental Study
}

\author{
Alfredo Alán Rey Calderón (iD and Alberto Díaz Díaz \\ Centro de Investigación en Materiales Avanzados, S. C. Miguel de Cervantes 120, Complejo Industrial Chihuahua, \\ 31136 Chihuahua, Chihuahua, Mexico \\ Correspondence should be addressed to Alberto Díaz Díaz; alberto.diaz@cimav.edu.mx
}

Received 18 June 2018; Revised 29 September 2018; Accepted 16 October 2018; Published 11 November 2018

Academic Editor: Jose M. Cabrera

Copyright ( 2018 Alfredo Alán Rey Calderón and Alberto Díaz Díaz. This is an open access article distributed under the Creative Commons Attribution License, which permits unrestricted use, distribution, and reproduction in any medium, provided the original work is properly cited.

\begin{abstract}
The aim of this paper was to analyze in detail the mechanical behavior of a polycarbonate by means of uniaxial tensile and compressive tests and to reveal new key aspects that must be taken into account in any predictive model. Uniaxial monotonic and creep-recovery tests were carried out at a variety of temperatures, stress levels, and load rates to get a complete description of the material response. Prior to mechanical testing, the material was subjected to a thermal rejuvenation in order to eliminate any previous aging and to obtain reliable and useful results. In every test, a complete determination of the strain state was assured by measuring axial and transverse strains with strain gauges. During the tests, significant asymmetry effects and viscous phenomena already reported by other authors were confirmed. The newest finding is that a nonlinear master transverse strain/axial strain curve matches perfectly with the experimental curves. This master curve is temperature- and rate-independent. Another originality of this paper is the disclosure of an instantaneous, hypoelastic-like behavior at high strain rates. The experimental observations presented in this study should be incorporated by a theoretical model whose aim is to accurately predict the mechanical behavior of polycarbonate subjected to any $3 \mathrm{D}$ stress state.
\end{abstract}

\section{Introduction}

A good mechanical design must offer a reliable performance which requires an extensive knowledge about how the material behaves. Many theoretical and experimental studies focused on the nonlinear behavior of polymers have been published. It is well known that mechanical behavior in polymers is complex: there is a dependency on strain rate [1-5]; temperature impacts the mechanical response [6-9]; moreover, hydrostatic stress affects mechanical behavior [10].

In most papers, the mechanical behavior of polymers has been studied under uniaxial stress states with a unique sign: tension or compression. Nevertheless, as Shaban states [11], only one type of experiment, commonly tension, is not enough to determine how the material behaves in different load settings. Several types of independent experiments, for example, compression, shear, and hydrostatic pressure, must be done in order to obtain a more complete characterization of materials. For example, McKenna and his coworkers $[12,13]$ studied the nonlinear viscoelastic behavior of specimens of some glassy polymers subjected to torsional tests in which the distance between the grips was fixed, in such a manner that a normal axial force was provoked. The derivatives of the strain energy density with respect to first and second invariants of the deformation tensor were obtained in an attempt to have a better understanding of the material behavior. In $[14,15]$, Knauss and Zhu carried out creep tests on a polycarbonate with different normal to shear stress ratios by means of an Arcan device and proved that the magnitude and sign of the hydrostatic stress have a very significant effect on creep behavior. An asymmetry effect occurs then in polycarbonate, and compressive tests are required to characterize the material behavior. Compressive tests that generate a quasiuniform uniaxial stress state may be hard to perform because of potential buckling and 
barreling effects, particularly for large strains. For this reason, Ravi-Chandar and Ma [16, 17] proposed original compressive tests with confined specimens in order to remove the aforementioned effects.

Another important aspect in the characterization of polymers that has been explored by several authors is the material response to multiple step loads [18-20]. When dealing with nonlinear materials, the application of a superposition principle is not valid. For polymer melts, it is well known that tests with reversing double step strain flows represent a challenge for those models willing to predict accurately the stress evolution; in these tests, "noninstantaneous chain retraction has complicated effects on the relaxation of stress" [19]. For polymer glasses, the understanding of the material response to multiple step loads is also necessary. McKenna and Zapas [12] carried out twostep relaxation tests with poly(methyl methacrylate) samples and adapted a model (the BKZ model [21]) to tests its accuracy in predicting the stress evolution. The model was able to predict the material behavior only if the material was subjected to previous mechanical conditioning; the model did not take into account the mechanical aging.

On the other hand, in some papers dealing with the modeling of the mechanical behavior of polymers, a constant Poisson's ratio is assumed. Apart from convenience, this may be due to the fact that many experimental studies dealing with mechanical tests on polymers do not include the measurement of transverse strains. In fact, for viscoelastic materials, Poisson's ratio is usually not constant and several authors have proved this for polymers [22-25]. For example, Tscharnuter et al. showed that for polypropylene, this ratio is rate- and temperature-dependent [22]. Pandini and coworkers $[23,24]$ proved that Poisson's ratios of poly (butylene terephthalate) and epoxy resins are timedependent. Additionally, in [25], Tschoegl et al. consider that in cyclic tests, Poisson's ratio of polymers depends on frequency. Mallon et al. [26] performed creep tensile and compressive tests on PMMA, PVC, and PP polymers and proved that Poisson's ratios vary in time and depend on the sign of the stress applied.

In this document, mechanical response of a polycarbonate (PC) subjected to uniaxial tensile and compressive loads is studied. The mechanical tests carried out are monotonic and creep-recovery tests at different temperatures. As mentioned before, the recovery stage in these last tests is a second load step that is useful to have a more complete characterization of PC. Prior to mechanical tests, specimens are rejuvenated by means of a thermal process. In every test, axial and transverse strains were measured in order to have a complete description of the strain state. In these tests, it can be observed that the viscous Poisson's ratio increases in compression, but remains virtually constant in tension. In fact, a nonlinear master transverse strain/axial strain curve is found. This result is one originality of the present paper. Another originality of this paper is the disclosure of an instantaneous, hypoelastic-like behavior at high strain rates. The experimentation including tensile and compressive tests at different load rates and temperatures with a complete strain state evaluation may help to enhance the current models of PC or to create new ones and to test the accuracy of their predictions.

This article is divided into 4 sections. First, research methods and materials are introduced, detailing heat treatments and tests carried out. Then, results obtained are presented highlighting the asymmetry effect of PC. Afterwards, a discussion of results which details some important implications for the modeling of the mechanical behavior of PC is presented. Finally, conclusions of this work are shown.

\section{Materials and Methods}

2.1. Materials. The study material is polycarbonate (PC) Makrolon GP solid, transparent, with smooth surface, manufactured by Bayer. Specimens were machined directly from PC plates. Sample dimensions are based on ASTM (American Society for Testing and Materials) standards; for tensile tests, a bone-shaped specimen with a cross-sectional area of $13.5 \mathrm{~mm} \times 3 \mathrm{~mm}$ inside a narrowed section was used [27]; for compressive tests, a rectangular specimen with a cross-sectional area of $25.4 \mathrm{~mm} \times 12.7 \mathrm{~mm}$ and $55 \mathrm{~mm}$ height was used [28].

Physical aging is a characteristic of glassy state, in which there is a progressive change in mechanical properties. These changes are caused by the existence of a free volume (volume that is not occupied by material molecules) due to an amorphous structure, like that of polymers. The presence of this free volume affects material density and therefore its mechanical properties. If a polymer is processed at high temperatures, it tends to reduce its specific volume when cooling. This reduction keeps happening when exposing the material to a constant aging temperature. This phenomenon causes a time-dependent mechanical behavior. It is worth mentioning that molecular composition is not affected, as it is with chemical aging (this is the case of thermal degradation and photo-oxidation). Physical aging effects can be reverted by means of a thermal rejuvenation [29]. This process consists of heating the sample to a temperature above glass transition temperature (Tg) during a meaningful period of time; in this way, the physical aging time is reinitiated and the effects of the observed phenomenon are erased. During a cooling process starting from a high temperature, the reduction rate of the specific volume decreases significantly at $\mathrm{Tg}$. This happens because above $\mathrm{Tg}$ (rubbery state), amorphous polymers are more flexible due to the initiation of a coordinated movement of large segments of material molecules [30]. Below Tg, the material state is known as glassy. In the present paper, the tests last less than 2 hours and for this reason, as suggested by McKenna [31], physical aging is neglected (physical aging times are usually 10 times greater than this test duration).

Before carrying out the mechanical tests, the material was subjected to a thermal treatment similar to that suggested by Struik [32] to rejuvenate it. This treatment consists of heating $\mathrm{PC}$ to $120^{\circ} \mathrm{C}$ for 24 hours and afterwards heating it to $155^{\circ} \mathrm{C}$ (value above the $\mathrm{Tg}$ ) for 24 hours. In order to determine the $\mathrm{Tg}$ of $\mathrm{PC}$, the following thermal analyses were done using a heating rate of $5^{\circ} \mathrm{C} / \mathrm{min}$ : differential scanning calorimetry (DSC) analysis, thermomechanical analysis 
(TMA), and a temperature scanning test in a dynamic mechanical analysis machine (DMA). All techniques provided virtually the same value of $\mathrm{Tg}, 140^{\circ} \mathrm{C}$. Moreover, a thermogravimetric analysis (TGA) was done to confirm that material does not suffer any degradation at $155^{\circ} \mathrm{C}$.

2.2. Uniaxial Mechanical Tests. Uniaxial tensile and compressive tests were carried out in a universal electromechanical testing machine, Instron 3318, in order to study the mechanical behavior of PC. The mechanical tests done were as follows:

(i) Monotonic tensile and compressive tests at different load rates: slow, moderate, and fast tests. In tension, three constant stress rates were applied: $1 \mathrm{MPa} / \mathrm{min}$ (slow), $10 \mathrm{MPa} / \mathrm{min}$ (moderate), and $100 \mathrm{MPa} / \mathrm{min}$ (fast). In compression, due to technical problems, the available universal testing machine was not able to control the tests with an assigned stress rate. For this reason, three strain rates were used in compression: $0.043 \% / \mathrm{min}$ (slow), $0.43 \% / \mathrm{min}$ (moderate), and $4.3 \% / \mathrm{min}$ (fast). Tests were carried out at four different temperatures: $25^{\circ} \mathrm{C}, 50^{\circ} \mathrm{C}, 70^{\circ} \mathrm{C}$, and $90^{\circ} \mathrm{C}$.

(ii) Short-term tensile and compressive creep tests with a recovery stage. Tests consisted of reaching certain stress level at a $9 \% / \mathrm{min}$ strain rate, afterwards sustaining such level for 30 minutes, then unloading at a $9 \% / \mathrm{min}$ strain rate to a zero stress state and finally sustaining the zero stress level for 1 hour to observe the material recovery. At room temperature $\left(25^{\circ} \mathrm{C}\right)$, stresses used were $30 \mathrm{MPa}, 35 \mathrm{MPa}, 40 \mathrm{MPa}, 45 \mathrm{MPa}$, $50 \mathrm{MPa}$, and $55 \mathrm{MPa}$. At $50^{\circ} \mathrm{C}, 70^{\circ} \mathrm{C}$, and $90^{\circ} \mathrm{C}$, the stress levels tested were $30 \mathrm{MPa}, 40 \mathrm{MPa}$, and $50 \mathrm{MPa}$. The creep-recovery tests considered herein are two-step loading tests. As mentioned in the introduction section, for polymer melts and glasses, the behavior prediction in reversing double-step strain flows represent a great challenge for theoretical models [12, 19]. Another test that would be interesting to perform is a multicreep test with a first tension step followed by a compression step. Nevertheless, this test is hard to perform because specimens for tensile tests have to be long enough to ensure a uniaxial stress state, and if these specimens were tested in compression, buckling would occur. It is for this reason that this load reversing test has not been performed herein.

In every case, strain gauges were used to measure the axial $\left(\varepsilon_{\mathrm{a}}\right)$ and transverse $\left(\varepsilon_{\mathrm{t}}\right)$ strains. Strains with a magnitude less than $5 \%$ are accurately measured with these gauges.

\section{Results}

3.1. Monotonic Tests. Figures 1(a), 1(b), and 1(c) show the stress $(\sigma)$ versus axial strain $\left(\varepsilon_{\mathrm{a}}\right)$ curves at different temperatures for slow, moderate, and fast monotonic tests, respectively. For all the load rates, it can be seen that the behavior is not linear elastic and that it depends on temperature: when temperature is increased, a same stress level provokes a higher axial strain. A difference in material behavior when subjected to tension or compression is also observed: a higher stress is necessary to provoke the same absolute value of axial strain under compression than that under tension; this confirms asymmetry effects on PC behavior. It is also worth mentioning that Young's modulus measured at the very beginning of the tests is virtually the same in tension and compression for all the temperatures and load rates tested, 2.3 GPa. Figures 2(a), 2(b), and 2(c) show the transverse strain $\left(\varepsilon_{\mathrm{t}}\right)$ versus axial strain $\left(\varepsilon_{\mathrm{a}}\right)$ curves for slow, moderate, and fast monotonic tests, respectively. For each load rate, the curves merge into a single master curve independent of temperature. In tension, a quasiconstant slope (its absolute value is 0.38 ) is obtained for the master curve whilst in compression, the absolute value of the slope starts with a 0.38 value and as the magnitude of the axial strain grows, it increases and reaches a 0.5 value, approximately. In linear elastic materials, Poisson's ratio is less than 0.5; herein, the material is not linear elastic and the abovementioned slope is not related to the classical Poisson's ratio $\nu=-\varepsilon_{\mathrm{t}} / \varepsilon_{\mathrm{a}}$ but to the viscous Poisson's ratio $\mu=-\dot{\varepsilon}_{\mathrm{t}} / \dot{\varepsilon}_{\mathrm{a}}$. The difference of the previous slopes in tension and compression is another evidence of asymmetry in material's behavior.

In Figures 3(a), 3(b), 3(c), and 3(d), the stress versus axial strain curves obtained in tension and compression for the different load rates at $25,50,70$, and $90^{\circ} \mathrm{C}$ are displayed, respectively. One can observe that at $25^{\circ} \mathrm{C}$, the curves merge virtually into a single master curve but for higher temperatures, significant differences appear in these curves for stresses having a magnitude greater than $40 \mathrm{MPa}$. As the temperature increases, the material behavior is more sensitive to the load rates considered. The transverse versus axial strain curves are not shown because the curves merge once again into a single master curve which becomes independent of temperature and load rate (this will be discussed in Section 4.3).

3.2. Creep Tests with Recovery. In this section, results of tensile and compressive creep tests with recovery at different stress levels and temperatures are presented. At instant $t=0 \mathrm{~s}$, a nonzero abrupt stress $\sigma$ is applied and maintained constant for 30 minutes. At $t=0 \mathrm{~s}$, the axial strain is $\varepsilon_{\mathrm{a}}^{0}$ and as time increases (for $t \leq 30 \mathrm{~min}$ ), a viscous strain $\varepsilon_{\mathrm{a}}^{v}(t)=$ $\varepsilon_{\mathrm{a}}(t)-\varepsilon_{\mathrm{a}}^{0}$ appears and grows (Figure 4). After this stage, the stress is removed and the strain is monitored for 1 hour. In Figure 4, the axial strain is plotted against time for the tensile test at $50 \mathrm{MPa}$ and $50^{\circ} \mathrm{C}$. During the nonzero stress stage, the maximum axial viscous strain $\varepsilon_{\mathrm{a}}^{v}$ attained is $0.23 \%$. Similar to Mindel and Brown's observations [33], at the end of the recovery stage, a persistent nonzero strain $\varepsilon_{\mathrm{a}}^{p}=0.06 \%$ remains. It is likely that this persistent strain is due to plasticity, and its magnitude may be neglected as compared with the maximum viscous strain attained. Similar results have been obtained for the tests carried out at the other stress levels and temperatures. For all these reasons, the behavior 


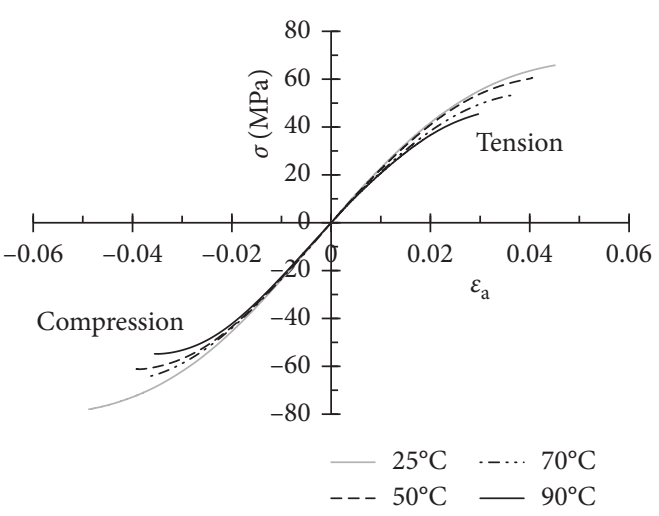

(a)

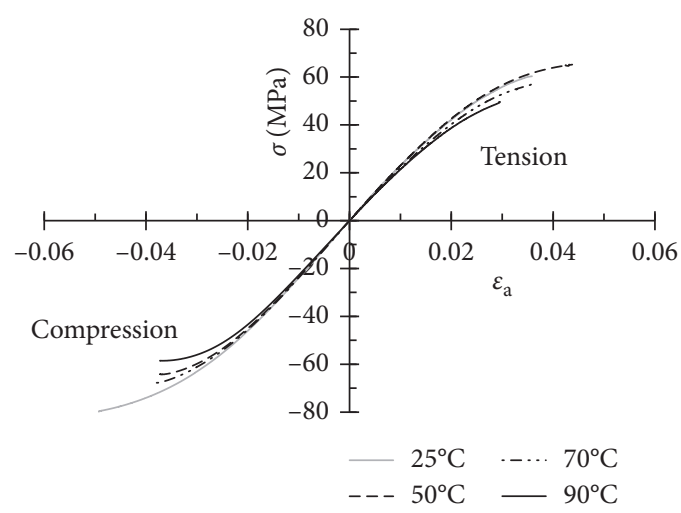

(b)

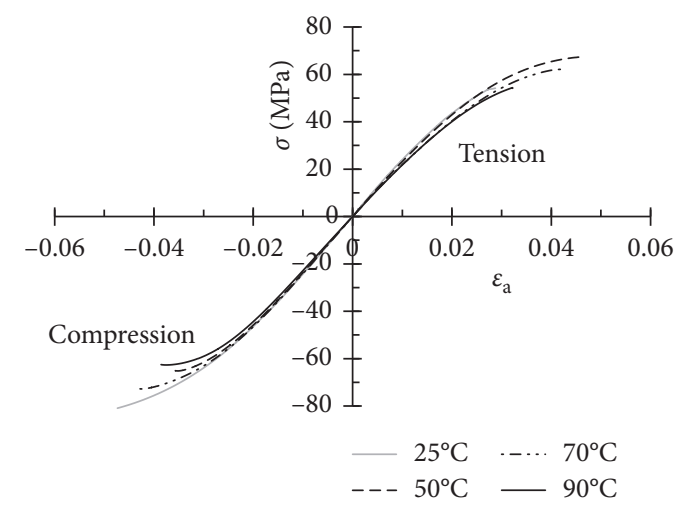

(c)

Figure 1: $\sigma$ vs $\varepsilon_{\text {a }}$ curves for slow (a), moderate (b), and fast (c) monotonic tests.

of PC is mainly viscoelastic. In what follows, only Figure 4 exhibits the evolution in time of the axial strain during the recovery stage. The plots of the transverse strain versus axial strain during the recovery stage obtained in these tests will be shown in Section 4.3.

During the application of the nonzero constant stress, it is useful to define the following axial creep compliance:

$$
J_{\mathrm{a}}=\frac{\varepsilon_{\mathrm{a}}}{\sigma} .
$$

Figures 5(a) and 5(b) present curves of axial creep compliances $\left(J_{\mathrm{a}}\right)$ against time at $25^{\circ} \mathrm{C}$ in tension and compression, respectively. The curves are significantly different: the magnitude of the creep compliance increases with the stress applied. This means that strains do not depend linearly on the applied stress $\sigma_{0}$ and since the material is quasiviscoelastic, the tests reveal a nonlinear viscoelastic behavior of PC in both tension and compression. These results are consistent with the observations of Jazouli et al. [34]; they showed that polycarbonate behavior in tension is linear for a stress level below $26 \mathrm{MPa}$ and nonlinear viscoelastic for a stress level above the previous value. Another important observation is that the curves in tension and compression for a same stress level are significantly different. This confirms asymmetry in the behavior of PC in creep tests.

In Figures 6(a), 6(b), and 6(c), the creep compliances are plotted against time for the different stress levels in tension at 50,70 , and $90^{\circ} \mathrm{C}$, respectively. It can be seen that as temperature or stress increases, the creep compliance increases. In Figure 6(c), in the tensile test carried out at $50 \mathrm{MPa}$ and $90^{\circ} \mathrm{C}$, the specimen failed abruptly at the beginning of the test and for this reason, the strain could not be monitored anymore. In Figures 7(a), 7(b), and 7(c), the creep compliances versus time curves are displayed for the different stress levels in compression at 50,70 , and $90^{\circ} \mathrm{C}$, respectively. Once again, a temperature or stress level increase provokes a creep compliance growth. The comparison of Figures 6 and 7 confirms once again the presence of asymmetry in the material behavior. The transverse strain versus time curves are not shown in this section because a master curve that enables deducing the transverse strain from the axial strain will be revealed in Section 4.3.

\section{Discussion}

In this section, the results obtained in the previous section are discussed.

4.1. Confirming Material Rejuvenation Usefulness. In some papers dealing with the mechanical characterization of PC, the authors do not specify whether they apply a rejuvenation process to the specimens or not. In order to assess the importance of the rejuvenation process, three additional monotonic tensile tests were performed using specimens in 


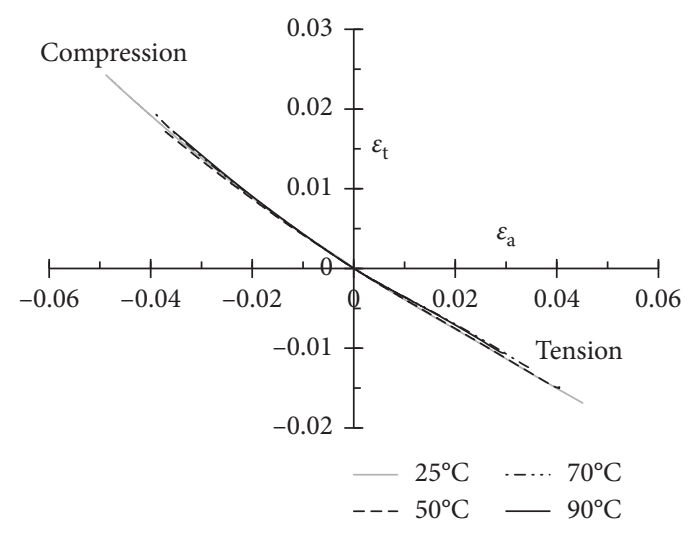

(a)

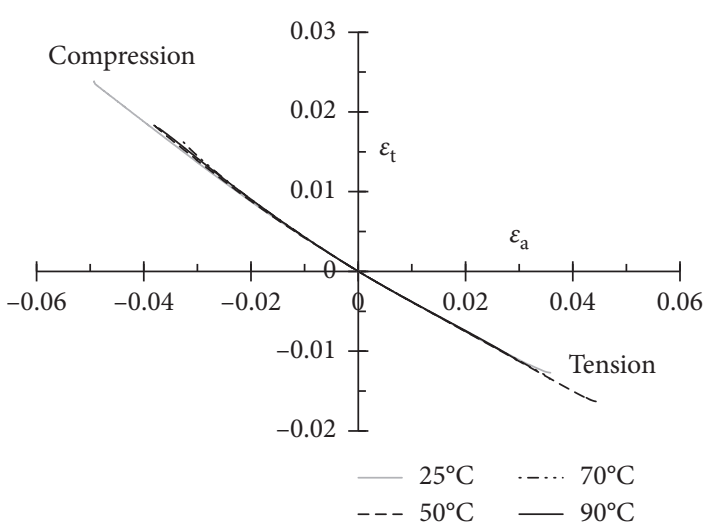

(b)

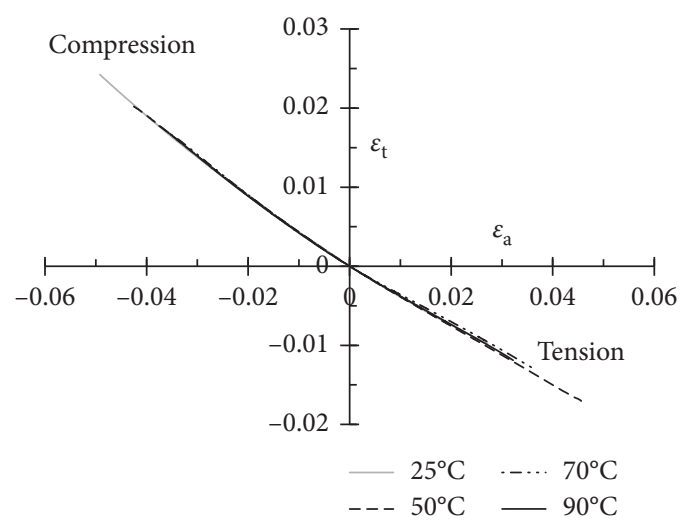

(c)

Figure 2: $\varepsilon_{\mathrm{t}}$ vs $\varepsilon_{\mathrm{a}}$ curves for slow (a), moderate (b), and fast (c) monotonic tests.

an as-received condition (aged specimens whose thermal history was unknown). Figure 8 shows stress versus axial strain curves in tension obtained with aged specimens tested at room temperature and three stress rates: $0.1,1$, and $10 \mathrm{MPa} / \mathrm{min}$. A stress/strain curve obtained in a slow test $(1 \mathrm{MPa} / \mathrm{min})$ with a rejuvenated specimen was added in the previous figure so as to notice the great difference in the material behavior when the material has aged. If the aging process is not controlled, the experimental results lack usefulness because the thermal history affecting material behavior is not registered. For this reason, any mechanical characterization of PC should include a thermal rejuvenation so as to reset the thermal history of the material.

4.2. Hypoelastic-Like Behavior and Its Effects. In Figure 3(a), the slow, moderate, and fast monotonic tests carried out at $25^{\circ} \mathrm{C}$ yield three curves that seem to merge into a single master curve. This may be due to the fact that these tests were performed at a high load rate and that viscous strains had not enough time to evolve during the test. In order to verify the existence of the master curve and to determine the nature of the nonlinearity in this master curve, an additional 3-cycle tensile test defined by the following steps was performed:

(1) Loading at a $3 \% / \mathrm{s}$ strain rate until a $50 \mathrm{MPa}$ stress was obtained, approximately
(2) Unloading at the same strain rate

(3) Recovery for 10 minutes

(4) Loading at a $1 \% / \mathrm{s}$ strain rate until a $50 \mathrm{MPa}$ stress was obtained, approximately

(5) Unloading at a $1 \% / \mathrm{s}$ strain rate

(6) Recovery for 10 minutes

(7) Loading at a $0.3 \% / \mathrm{s}$ strain rate until a $50 \mathrm{MPa}$ stress was obtained, approximately

(8) Unloading at a $0.3 \% / \mathrm{s}$ strain rate

(9) Recovery for 10 minutes

The strain rates considered above yield higher stress rates (at least, 4 times greater) than those applied in Section 3.1. In Figure 9(a), the stress is plotted against the axial strain obtained in the cyclic test at $25^{\circ} \mathrm{C}$. The line style corresponding for each cycle in the previous figure has been changed so as to ease their identification. Since these curves overlap, in Figure 9(b), an artificial horizontal 0.5\% shift has been applied to visualize the curve obtained in each cycle. Virtually, a same curve is obtained in each cycle. Similar curves were obtained in compression and at higher temperatures: $50^{\circ} \mathrm{C}, 70^{\circ} \mathrm{C}$, and $90^{\circ} \mathrm{C}$ (not shown in this paper).

Let us describe the stress-strain curves for each loadingunloading-recovery cycle. During the loading stage, a first linear elastic behavior stage appears for stresses less than 


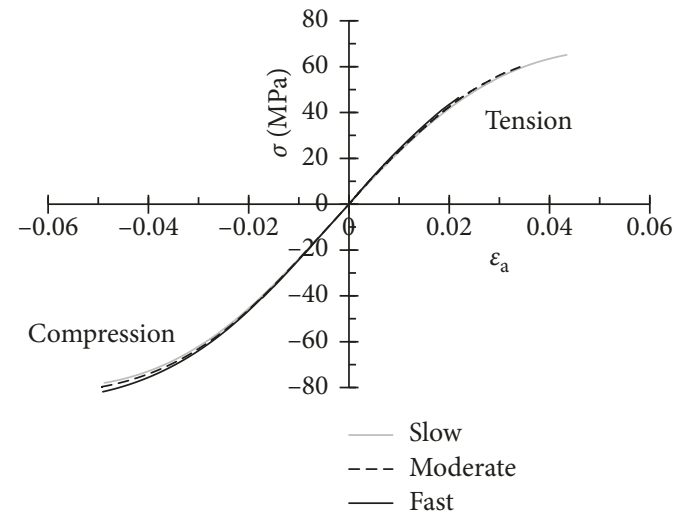

(a)

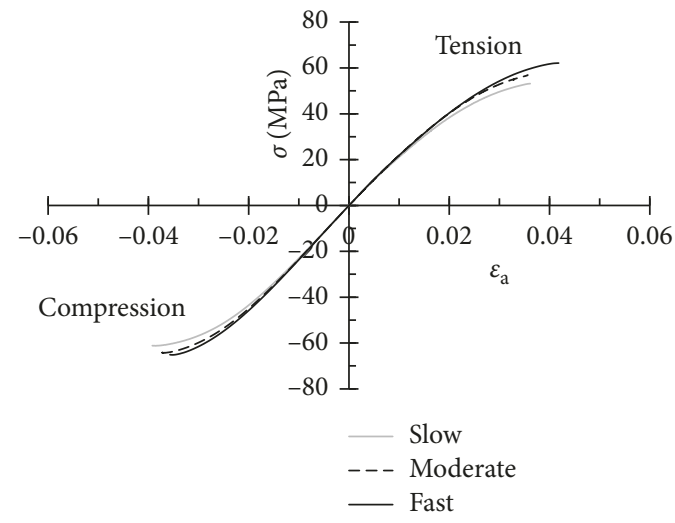

(c)

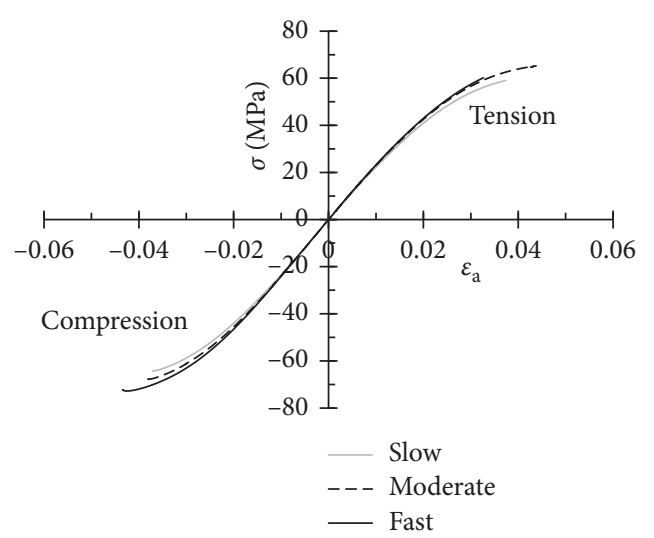

(b)

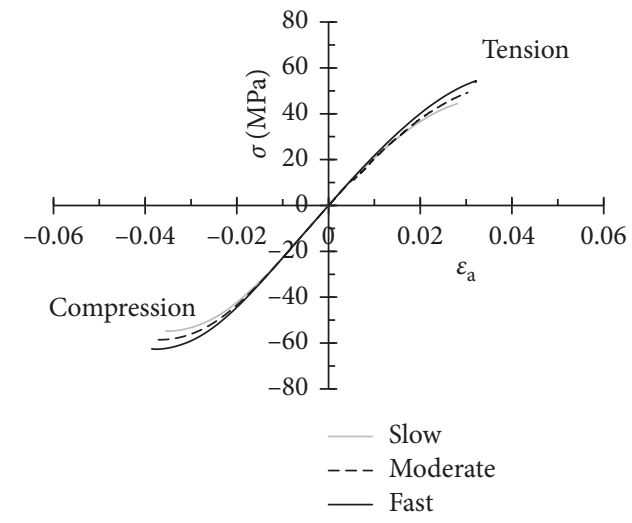

(d)

Figure 3: $\sigma$ vs $\varepsilon_{\mathrm{a}}$ curves at $25^{\circ} \mathrm{C}$ (a), $50^{\circ} \mathrm{C}(\mathrm{b}), 70^{\circ} \mathrm{C}(\mathrm{c})$, and $90^{\circ} \mathrm{C}(\mathrm{d})$ in tension and compression for different load rates.

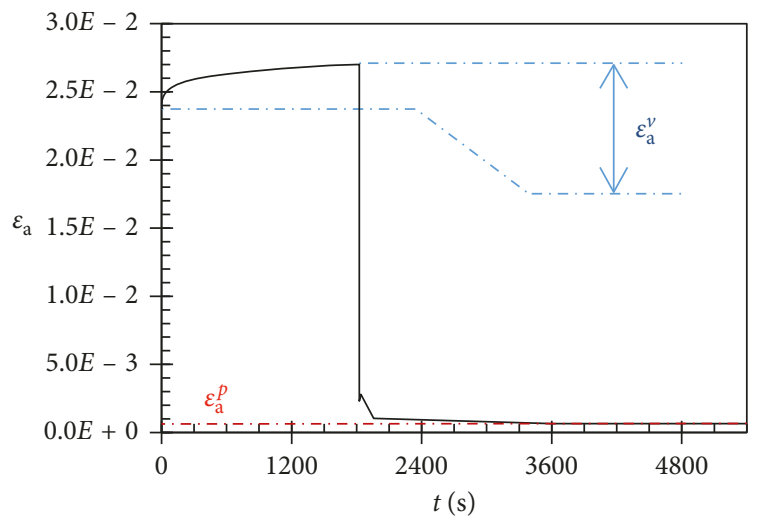

FIgURE 4: $\varepsilon_{\mathrm{a}}$ vs time curve for a tensile creep test at $50 \mathrm{MPa}$ and $50^{\circ} \mathrm{C}$.

$30 \mathrm{MPa}$ (a $2.3 \mathrm{GPa}$ elastic modulus is deduced); after this, a nonlinear behavior is obtained. At $50 \mathrm{MPa}$, the axial strain is $12 \%$ greater than the expected linear elastic strain $\varepsilon^{l}$, as shown in Figure 9(a). The unloading follows a slightly different path from the loading stage and it yields also a nonlinear curve. At the end of the unloading stage, a small axial strain remains, and it marginally decreases during the recovery stage leaving a small persistent strain. The second cycle starts then from a nonzero strain and displays virtually the same stress strain-curve as the first cycle but shifted to the right due to the initial strain. The same happens for the third cycle. Let us provide an explanation to these curves. Since all cycles yield virtually the same stress-strain curve, the material behavior does not depend on the loading rates tested during loading and unloading stages, and therefore the nonlinearity is not due to viscous phenomena. Loading and unloading follow almost the same path, and therefore a hypoelastic component in the material behavior can be inferred. After loading and unloading, a very small strain remains; this strain is surely due to an instantaneous dissipative phenomenon such as plasticity. In this manner, hypoelasticity combined with a marginal plasticity can explain the shape of the curves during the loading and unloading stages. A further analysis, out of the scope of this paper, is required to make a better a characterization of the hypoelastic-like behavior of PC at high strain rates. Let us now analyze the stress-free recovery stage. This stage starts with an initial plastic strain that produces a viscous strain smaller than the initial plastic strain. In Figure 10(a), the axial strain is plotted against time during the first recovery stage. The axial strain starts with an instantaneous plastic strain, decreases during 300 seconds, and then remains virtually constant and equal to a nonzero plastic strain. It is for this reason that the curves are shifted to the right after each cycle. 


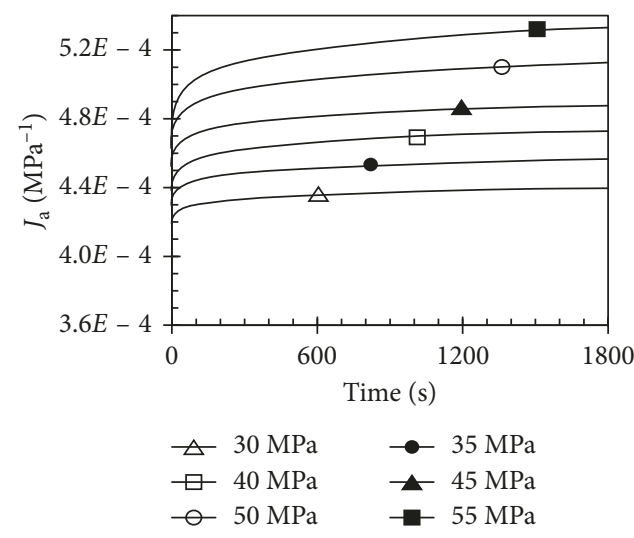

(a)

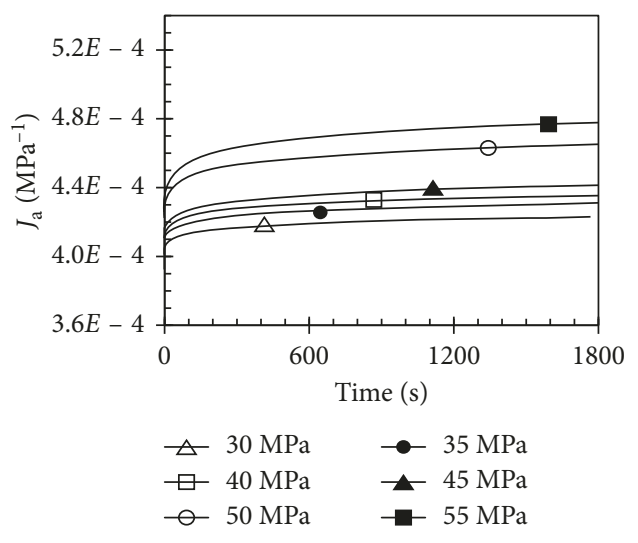

(b)

Figure 5: Axial creep compliance $J_{\mathrm{a}}$ vs. time curves in tension (a) and compression (b) at $25^{\circ} \mathrm{C}$.

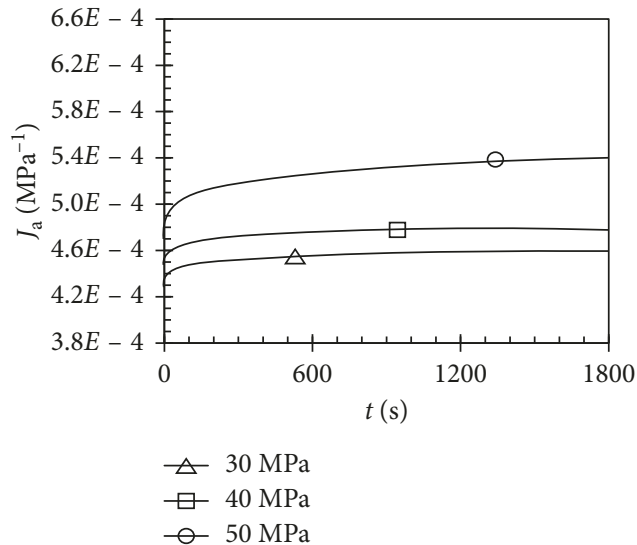

(a)

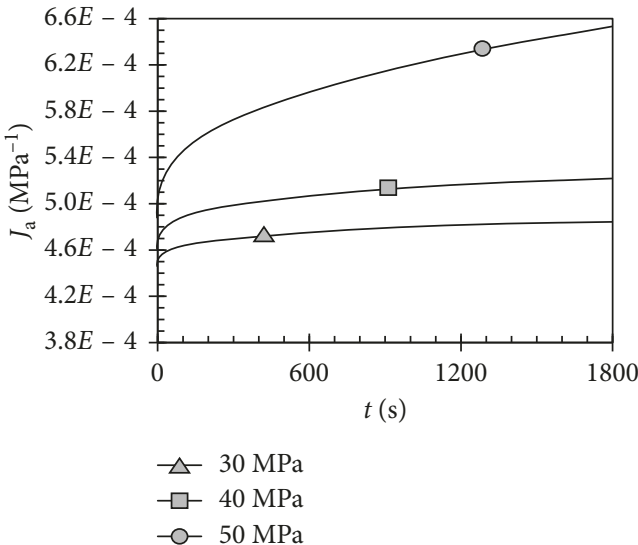

(b)

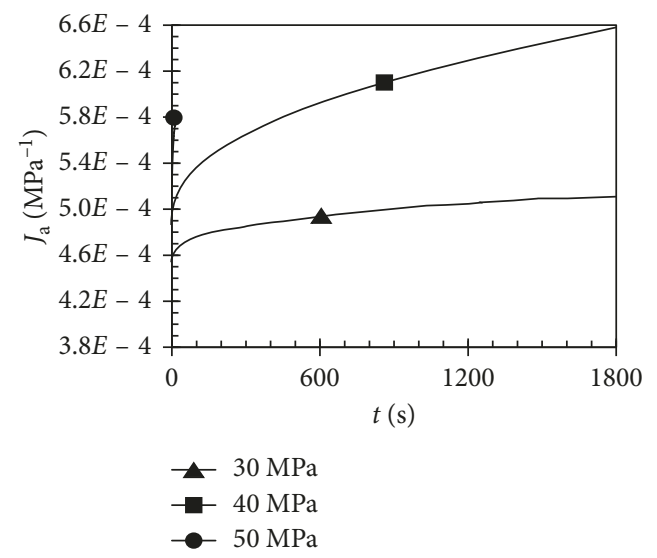

(c)

Figure 6: Axial creep compliance $J_{\mathrm{a}}$ vs. time curves in tension at $50^{\circ} \mathrm{C}$ (a), $70^{\circ} \mathrm{C}$ (b), and $90^{\circ} \mathrm{C}$ (c).

The master curve in Figure 3(a) that was inferred in monotonic tests at $25^{\circ} \mathrm{C}$ is easily explained by the hypoelastic-like behavior (nonlinear quasielastic behavior). As shown in Figure 10(b), the stress-strain curves obtained in Figure 3(a) in tension are not significantly different from that using the $3 \% / \mathrm{s}$ strain rate applied in the first loading stage of the cyclic test. In Figure 11, the inferred stress vs. axial strain master curve obtained during a monotonic test using a 3\%/s strain rate is shown; the results obtained in compression are included in this figure. At lower stress rates than the slowest one considered, higher viscous strains would appear. At higher temperatures, viscous phenomena are more significant, and a rate-dependent behavior is shown in Figures 3(b), 3(c), and 3(d). Nevertheless, a master 


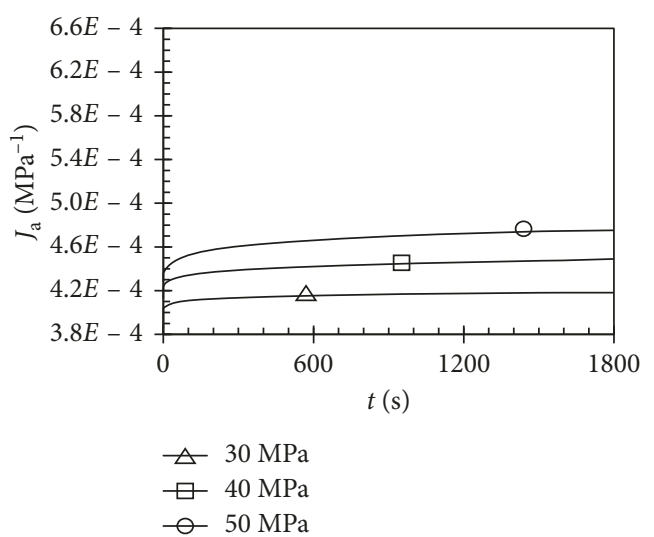

(a)

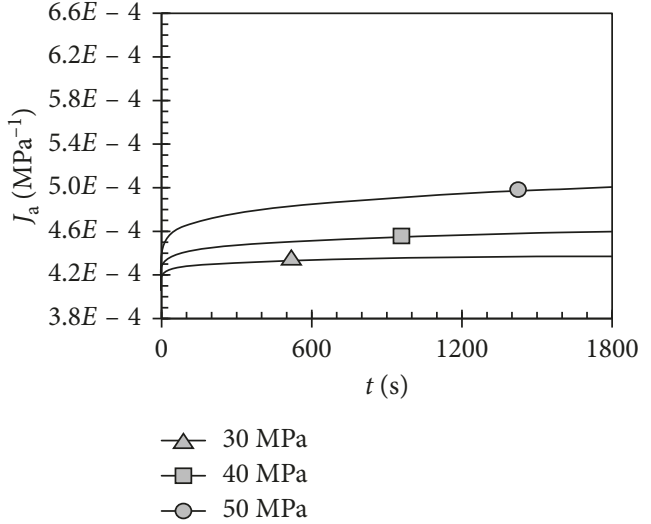

(b)

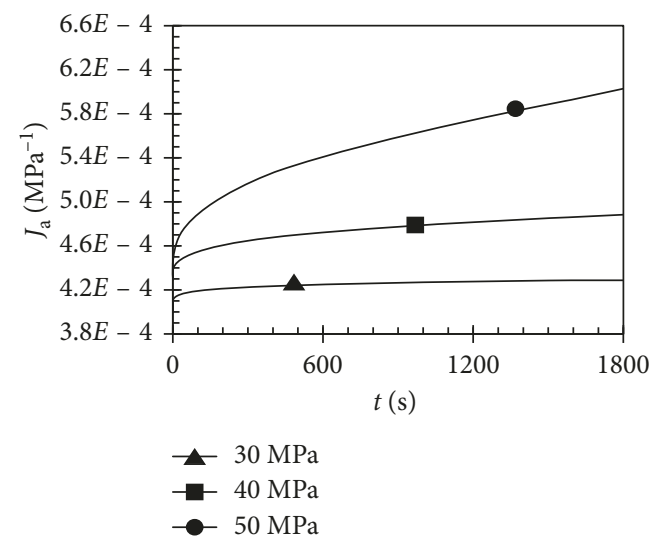

(c)

Figure 7: Axial creep compliance $J_{\mathrm{a}}$ vs. time curves in compression at $50^{\circ} \mathrm{C}(\mathrm{a}), 70^{\circ} \mathrm{C}$ (b), and $90^{\circ} \mathrm{C}$ (c).

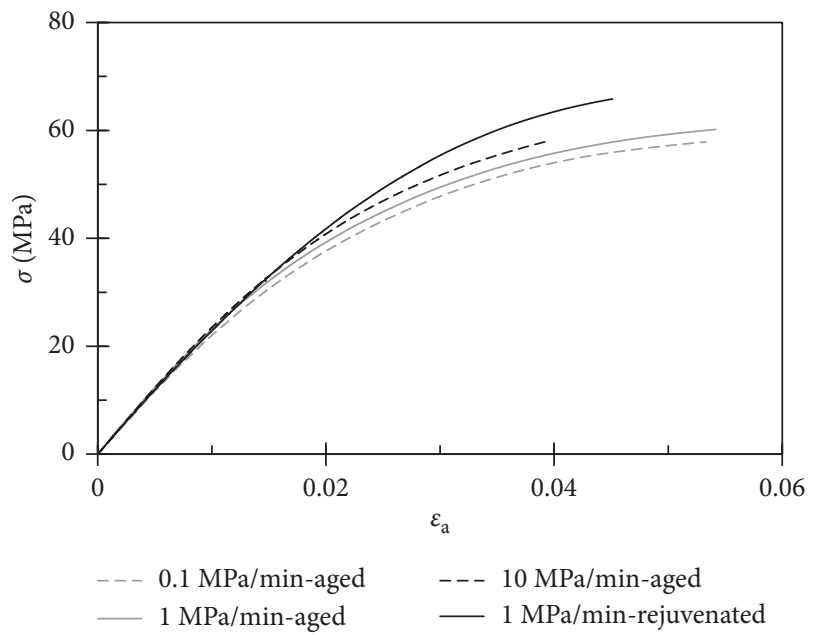

Figure 8: $\sigma$ vs $\varepsilon_{\mathrm{a}}$ curves in tensile tests at $25^{\circ} \mathrm{C}$ with aged and rejuvenated specimens.

curve exists and is obtained by carrying out the tests at higher load rates as the $3 \% / \mathrm{s}$ applied in the cyclic test.

It is also interesting to notice the effects of the hypoelastic-like behavior of PC at high strain rates in the axial creep compliance $J_{\text {a }}$ curves obtained in Figures 5, 6, and 7. At the same temperature, in tensile and compressive tests, the sudden load provokes an initial axial strain that is greater than the predicted linear elastic strain due to the hypoelastic-like behavior. It is for this reason that the initial creep compliance $J_{\mathrm{a}}$ increases as the applied stress increases.

4.3. Transverse versus Axial Strains Master Curve. Figures 2(a), 2(b), and 2(c) proved that in monotonic tests, the transverse versus axial strains curves obtained at different temperatures merged into a master curve for a given load rate. Let us now plot the curves for all the load rates and temperatures in Figure 12. In this figure, it can clearly be seen that theses curves do not depend on the load rate and temperature and that they all describe a same master curve. The curve is linear in tension but nonlinear in compression. For this reason, in compression, time-dependent Poisson's ratios would be obtained.

It is natural to ask oneself if this master curve keeps its uniqueness for the creep tests performed at different stress levels and temperatures. In Figure 13, the transverse versus axial strains curves obtained at $25^{\circ} \mathrm{C}$ are plotted with the master curve obtained in the monotonic tests. In this figure, only the evolution of strains in the nonzero stress stage is considered so as to solely visualize the evolution due to viscous strains. The master curve matches perfectly with the 


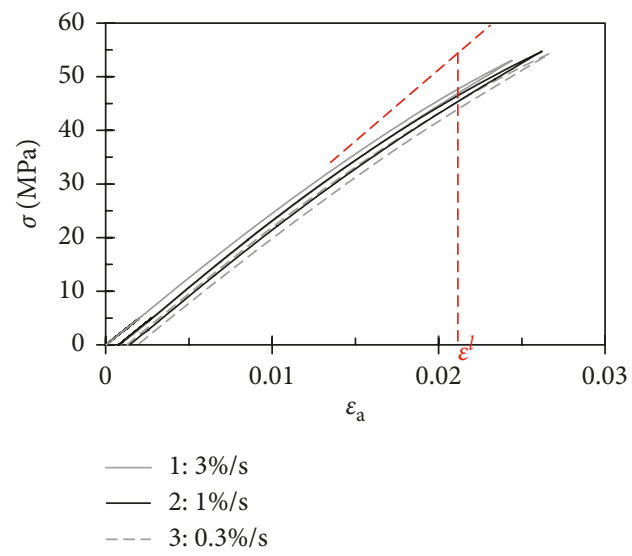

(a)

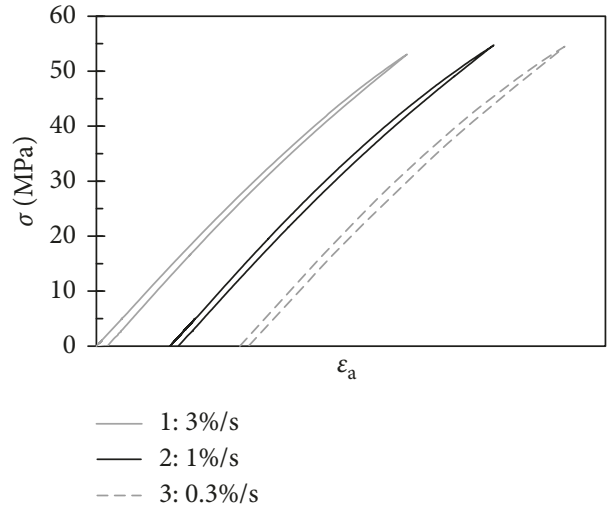

(b)

Figure 9: $\sigma$ vs $\varepsilon_{\text {a }}$ curves obtained during a 3-cycle tensile test at $25^{\circ} \mathrm{C}$ (a) and with a horizontal shifting to distinguish the curve in each cycle (b).

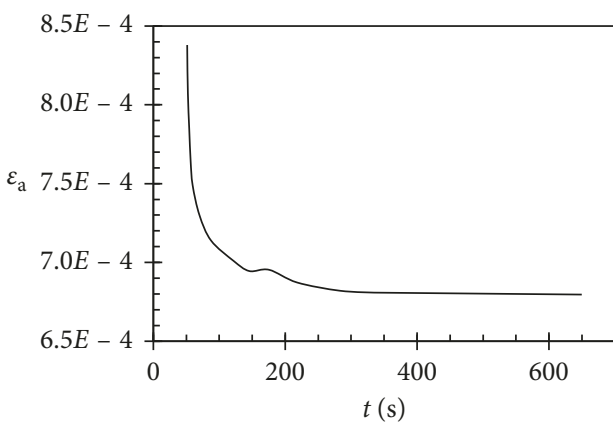

(a)

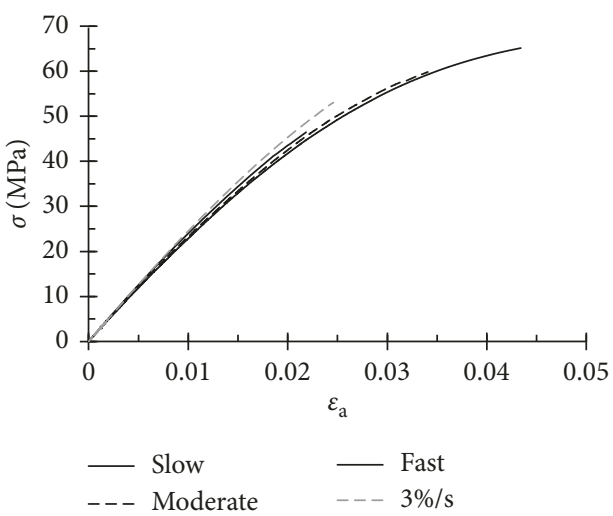

(b)

FiguRE 10: $\varepsilon_{\mathrm{a}}$ vs $t$ curve in the first recovery stage (a); $\sigma$ vs $\varepsilon_{\mathrm{a}}$ curves obtained in slow, moderate, fast, and ultrafast monotonic tensile tests at $25^{\circ} \mathrm{C}(\mathrm{b})$.

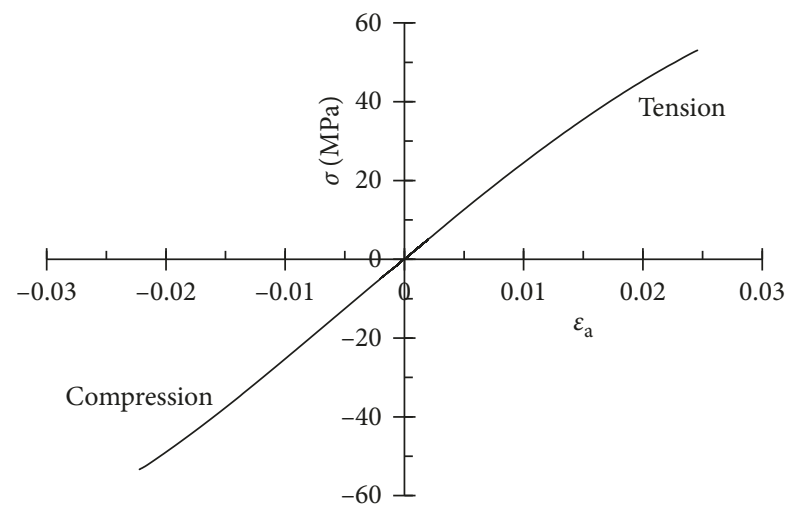

FIGURE 11: $\sigma$ vs $\varepsilon_{\mathrm{a}}$ master curve at high strain rates.

experimental creep test curves. In Figures 14(a), 14(b), and 14(c), the transverse versus axial strains curves obtained at 50, 70, and $90^{\circ} \mathrm{C}$ are plotted with the master curve, respectively. Once again, the master curve reproduces

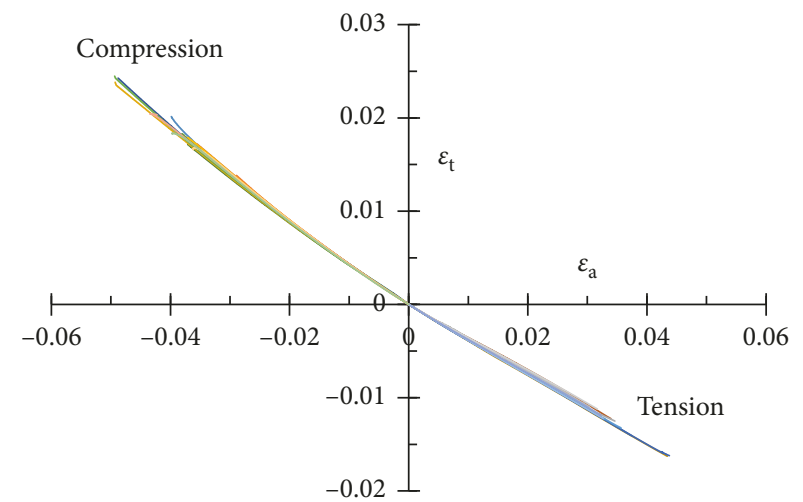

FIGURE 12: $\varepsilon_{\mathrm{t}}$ vs $\varepsilon_{\mathrm{a}}$ curves obtained in all monotonic tests and merge into a single master curve.

perfectly the experimental curves. Additionally, one can argue that a small increase in the viscous strains can hardly provoke that the experimental creep curves separate from 


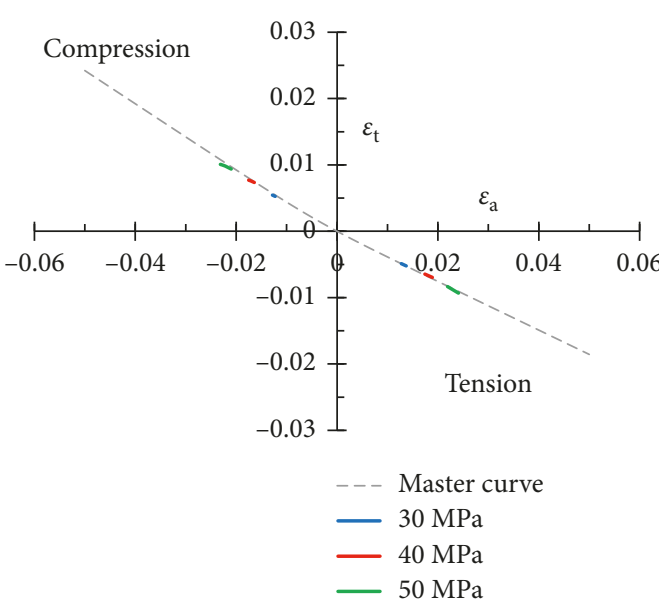

(a)

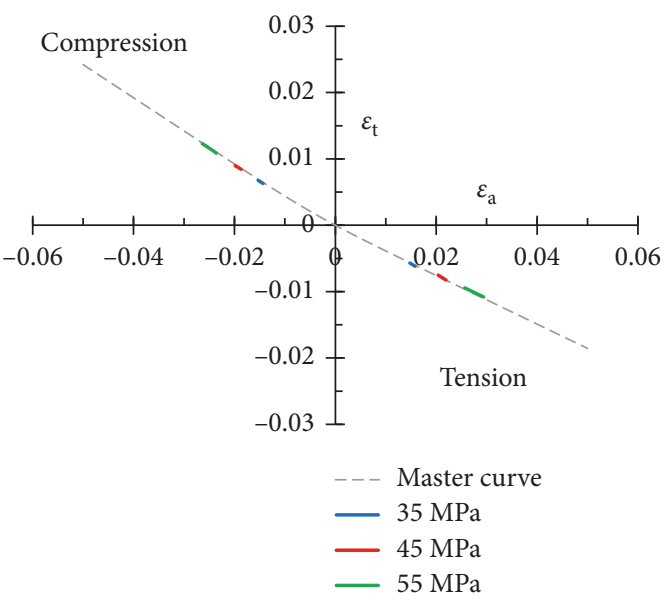

(b)

FiguRe 13: $\varepsilon_{\mathrm{t}}$ vs $\varepsilon_{\mathrm{a}}$ master and experimental curves obtained in 30,40 , and $50 \mathrm{MPa}$ (a) creep tests and 35 , 45, and $55 \mathrm{MPa}$ (b) creep tests at $25^{\circ} \mathrm{C}$.

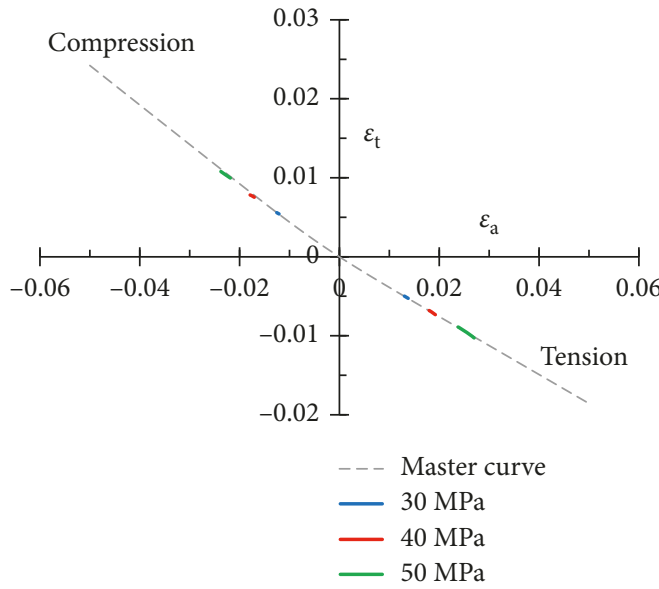

(a)

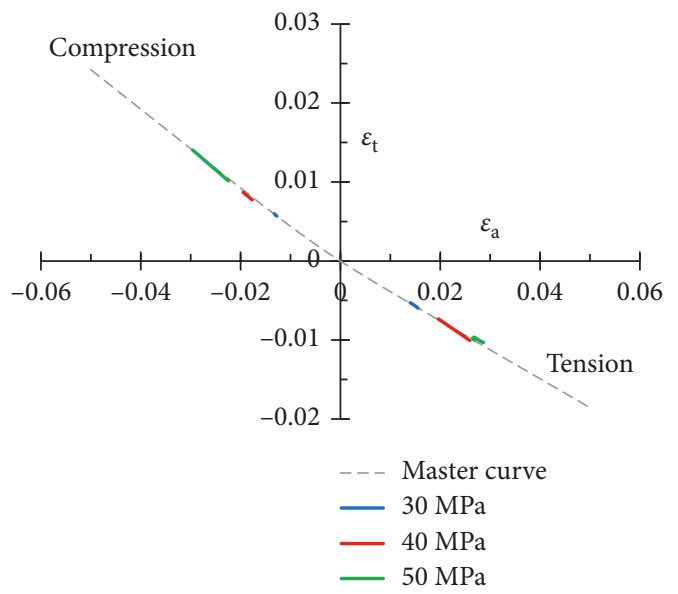

(c)

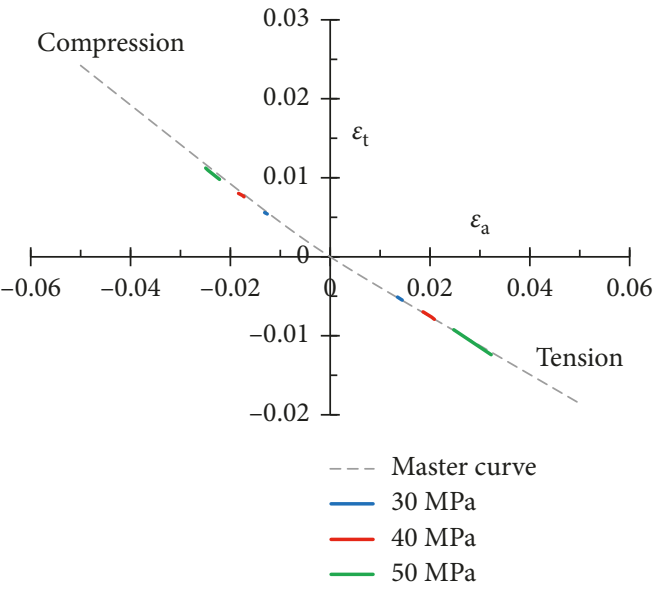

(b)

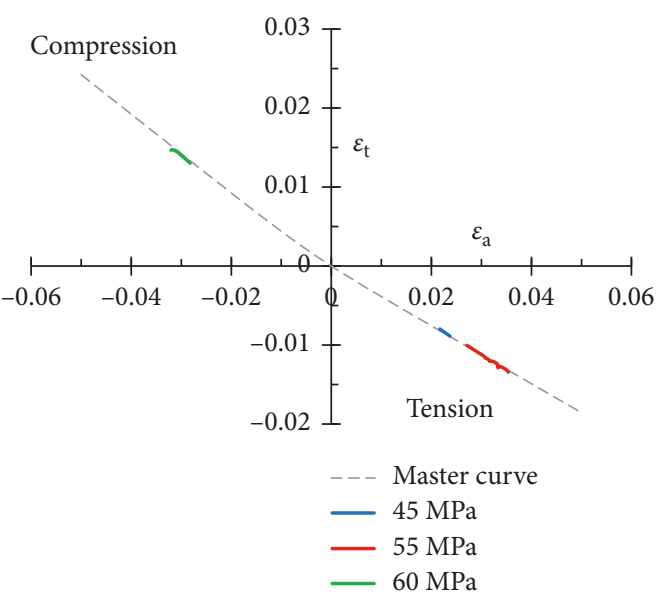

(d)

Figure 14: $\varepsilon_{\mathrm{t}}$ vs $\varepsilon_{\mathrm{a}}$ master and experimental curves obtained in creep tests at $50^{\circ} \mathrm{C}(\mathrm{a}), 70^{\circ} \mathrm{C}(\mathrm{b})$, and $90^{\circ} \mathrm{C}(\mathrm{c})$; long-term creep tests at $25^{\circ} \mathrm{C}(\mathrm{d})$. 
the master one. For this reason, additional $24 \mathrm{~h}$ creep tests followed by a $48 \mathrm{~h}$ recovery stage were carried out at $25^{\circ} \mathrm{C}$ using three stress levels: 45,55 , and $60 \mathrm{MPa}$. The first two tests were tensile tests whilst the latter was a compressive one. In Figure 14(d), the transverse versus axial strains curves obtained in the long-term creep tests during the first step (nonzero stress stage) are plotted with the master curve. Again, the master curve matches perfectly with the long-term creep curves. Finally, let us verify that the master curve remains valid during the recovery stage of the creeprecovery tests. In Figure 15, the transverse versus axial strains curves obtained during the recovery stage in all the short-term tests are plotted with the master curve. In Figure 16, the transverse versus axial strains curves obtained in the long-term tests are shown. The master curve matches perfectly with the recovery curves. Consequently, the $\varepsilon_{\mathrm{t}}$ versus $\varepsilon_{\mathrm{a}}$ master curve seems to be a property of PC in uniaxial tests that does not depend on temperature, nor on the loading rate. An additional analysis, out of the scope of this paper, is required to express this original result in terms of strain invariants so as to include it in a model aiming to predict the mechanical behavior of PC in a $3 \mathrm{D}$ stress state.

It is worth mentioning that since the volumetric strain $\varepsilon_{\mathrm{v}}$ is equal to $\varepsilon_{\mathrm{a}}+2 \varepsilon_{\mathrm{t}}$, a master $\varepsilon_{\mathrm{v}}$ versus $\varepsilon_{a}$ curve exists for the uniaxial tests considered herein; this curve is shown in Figure 17. It can be observed that in tension, as $\varepsilon_{\mathrm{a}}$ increases, the volume increases proportionally. In compression, for $\left|\varepsilon_{\mathrm{a}}\right|<\sim 1 \%$, as $\varepsilon_{\mathrm{a}}$ decreases, the volume decreases, but for $\left|\varepsilon_{\mathrm{a}}\right|>\sim 2 \%$, the volumetric strain remains virtually constant. Let us compare these results to those obtained by Colucci et al. in [35] for two types of PC (PC1 and PC2) tested in stress relaxation tests. Colucci et al. showed an isochronal $\varepsilon_{\mathrm{v}}$ versus $\varepsilon_{\mathrm{a}}$ curve at $0.5 \mathrm{~s}$ analogue to our curve in Figure 17. In tension, our material has a similar behavior to that of PC1; PC2 exhibits a densification beyond a certain axial strain level which does not appear herein. In compression, this time, our material behaves like PC2; PC1 exhibits a monotonic volume reduction as $\varepsilon_{\mathrm{a}}$ decreases. As suggested by Colucci et al. it is possible that the differences in the molecular weights and their distribution may be the cause of the dissimilar behavior of these materials. The determination of the molecular weight of the PC tested herein and its influence on the material behavior are out of the scope of this paper.

4.4. Implications for Modeling PC Behavior. The experimental results obtained in this paper imply that any modeling aiming to predict accurately the mechanical behavior of PC in a 3D stress state at temperatures below $\mathrm{Tg}$ and above room temperature must take into account the following:

(i) A nonlinear instantaneous hypoelastic-like response, the effects of hydrostatic stresses (asymmetry), temperature, and load rates on viscoelastic behavior.

(ii) Poisson's ratio may be considered constant in tension but not in compression. (iii) The existence of a master transverse strain/axial strain curve (a material property) in uniaxial tests. This curve must be interpreted in terms of strain invariants.

(iv) The persistence of small strains that might be due to plasticity. Depending on the accuracy level of the model, these strains may be neglected.

Flory and McKenna [13] tested a PC and proved that the strain energy density virtually does not depend on the second invariant of the deformation tensor and the first invariant does have a significant effect on the strain energy density for the tests considered by these authors. A neoHookean behavior may thus be inferred for this material, and if one adopts a neo-Hookean model, the expression of the strain energy density as a function of the first invariant of the deformation tensor has to be determined in such a manner that the model could fit the experimental curves. Another interesting approach which can be adopted to model PC behavior is the one proposed by Caruthers et al. in [36]. The approach is developed on a rational mechanics framework to ensure thermodynamic consistency. This approach requires a proposal for the expression of the Helmholtz free energy density to obtain the constitutive equations. For the PC tested herein, the application of such models to the uniaxial tests has to reproduce the master transverse strain/axial strain curve and the instantaneous response shown in Figure 11. This is not a simple task and represents an interesting challenge that will be tackled in a future paper.

\section{Conclusions}

In this study, the mechanical behavior of polycarbonate (PC) was investigated by means of uniaxial tensile and compressive tests at various load rates and temperatures below $\mathrm{Tg}$. From the experimental work, the following conclusions can be drawn:

(1) As observed by other authors, a marked asymmetry effect on PC's behavior is confirmed.

(2) An asymmetry effect exists on the viscous Poisson's ratio of PC: in tension it remains constant and equal to 0.38 , but in compression it increases up to 0.5 approximately.

(3) A master transverse strain/axial strain curve is revealed. Whatever the test, load rate, and temperature, the experimental curve is perfectly described by the master curve. The inclusion of this original result in a 3D stress state model requires an additional analysis to express the meaning of the master curve in terms of strain invariants.

(4) Within the stress and strain ranges considered in this paper, PC exhibits a viscoelastic behavior for low load rates and an instantaneous, nonlinear, hypoelastic-like behavior for high load rates.

(5) Tests' results are reliable, because the material was subjected to thermal rejuvenation before the tests, so 


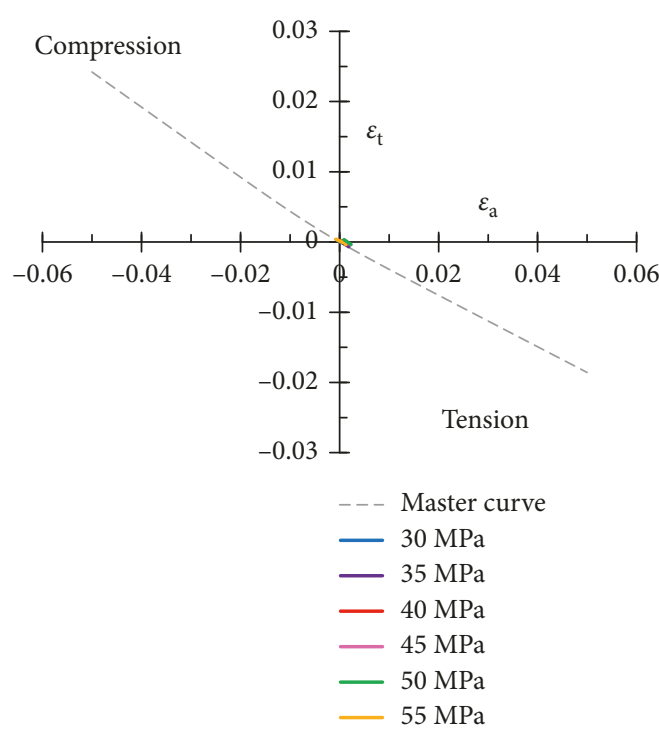

(a)

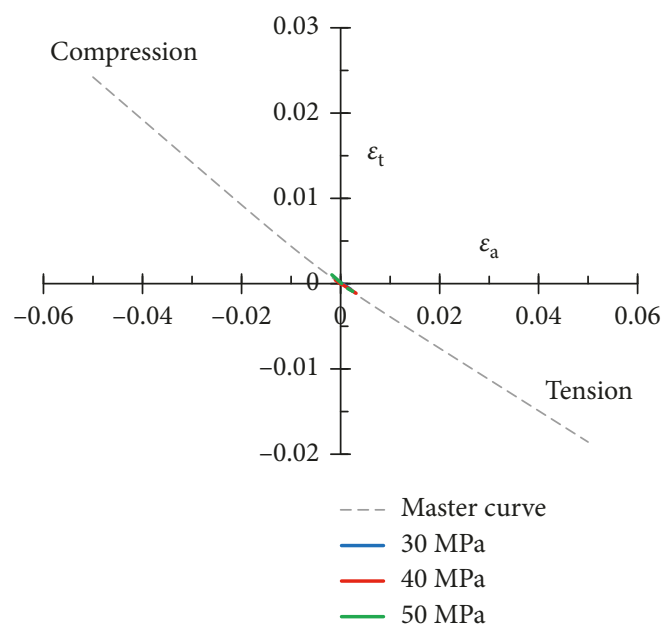

(c)

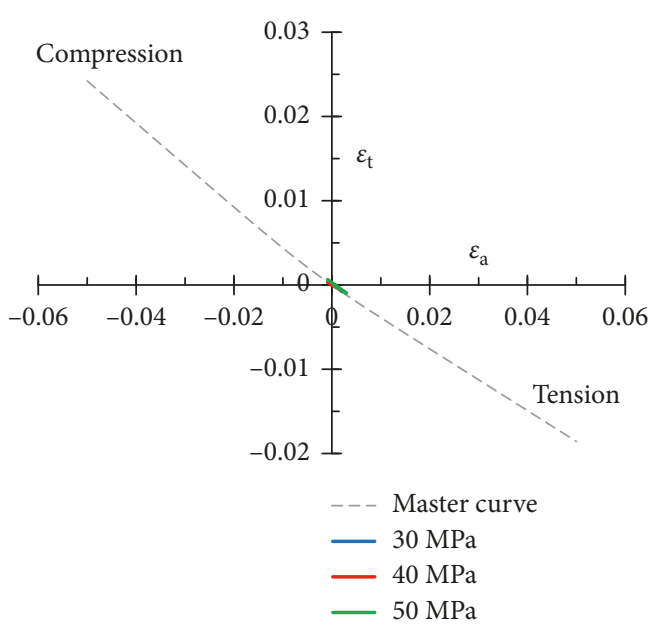

(b)

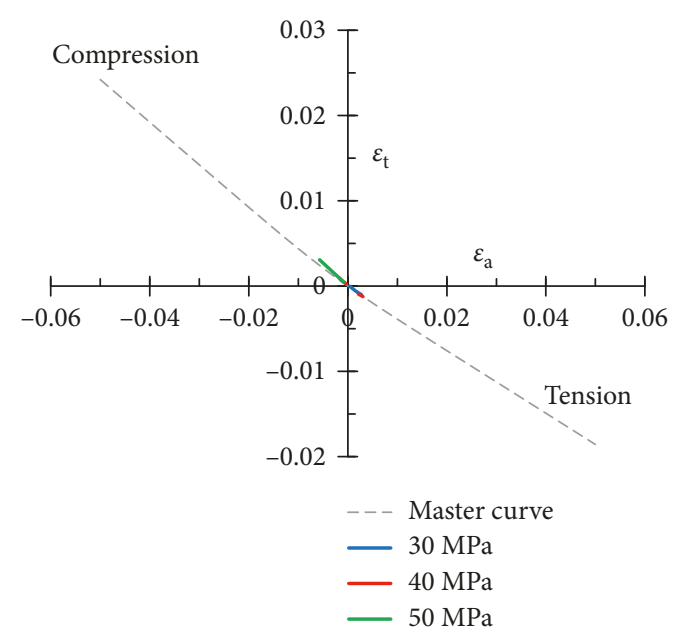

(d)

FIgURE 15: $\varepsilon_{\mathrm{t}}$ vs $\varepsilon_{\mathrm{a}}$ master and experimental curves obtained in creep-recovery tests at (a) $25^{\circ} \mathrm{C}$, (b) $50^{\circ} \mathrm{C}$, (c) $70^{\circ} \mathrm{C}$, and $(\mathrm{d}) 90^{\circ} \mathrm{C}$.

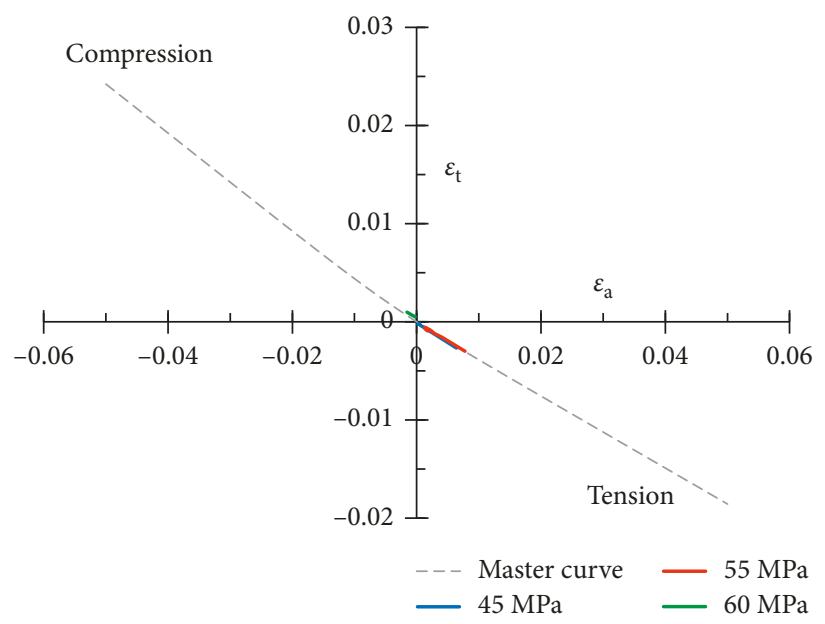

Figure 16: $\varepsilon_{\mathrm{t}}$ vs $\varepsilon_{\mathrm{a}}$ master and experimental curves obtained in long-term creep-recovery tests at $25^{\circ} \mathrm{C}$. 


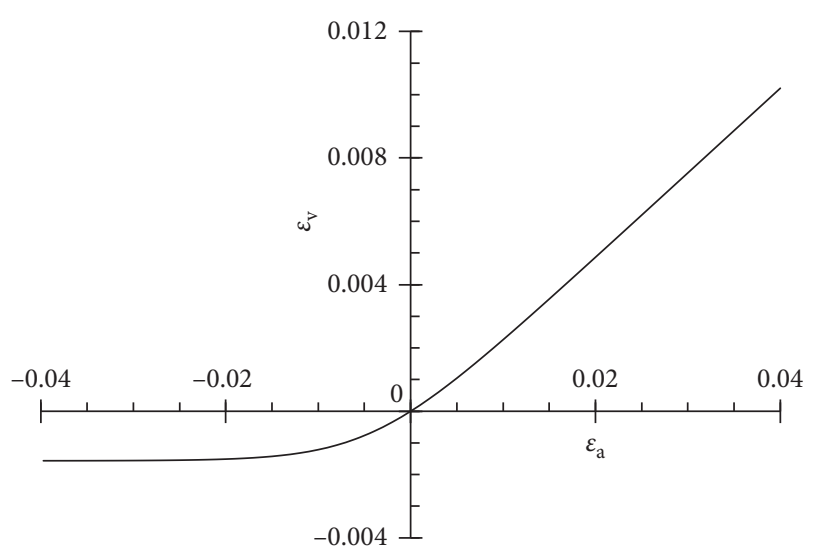

FIgURE $17: \varepsilon_{\mathrm{v}}$ versus $\varepsilon_{\mathrm{a}}$ master curve.

the previous history of material was erased, reestablishing its original properties and eliminating changes due to physical aging.

These results should be considered in any model aiming to predict accurately PC behavior. The results of other tests such as combined torsion/tension tests and cyclic uniaxial tests with reverse loadings (tension/compression) should also be considered in a modeling stage so as to obtain reliable predictions for PC subjected to multiaxial stress states with cyclic loading. In a future paper, a model including these recommendations will be developed.

It is not sure that the observed phenomena for PC are valid for other glassy state polymers as well. PC is a very particular polymer exhibiting global thermorheological simplicity [37] and for which $\beta$-relaxations are negligible [13]. To confirm this, the methods and tests proposed in this paper can be replicated with other glassy polymers.

\section{Data Availability}

The experimental data used to support the findings of this study are included within the article.

\section{Conflicts of Interest}

The authors declare that there are no conflicts of interest regarding the publication of this paper.

\section{Acknowledgments}

The authors gratefully acknowledge Rubén Castañeda Balderas for carrying out the tests exhibited in this paper. The authors would also like to acknowledge CONACYT for its financial support.

\section{References}

[1] L. Cangemi, S. Elkoun, C. G'Sell, and Y. Meimon, "Volume strain changes of plasticized poly(vinylidene fluoride) during tensile and creep tests," Journal of Applied Polymer Science, vol. 91, no. 3, pp. 1784-1791, 2004.

[2] A. D. Drozdov and Q. Yuan, "The viscoelastic and viscoplastic behavior of low-density polyethylene," International Journal of Solids and Structures, vol. 40, no. 1, pp. 2321-2342, 2003.
[3] O. U. Colak, "Modeling deformation behavior of polymers with viscoplasticity theory based on overstress," International Journal of Plasticity, vol. 21, no. 1, pp. 145-160, 2005.

[4] K. Cao, X. Ma, B. Zhang, Y. Wang, and Y. Wang, "Tensile behavior of polycarbonate over a wide range of strain rates," Materials Science and Engineering A, vol. 527, no. 16-17, pp. 4056-4061, 2010.

[5] A. Schiavi, R. Cuccaro, and A. Troia, "Strain-rate and temperature dependent material properties of Agar and Gellan Gum used in biomedical applications," Journal of the Mechanical Behavior of Biomedical Materials, vol. 53, pp. 119130, 2016.

[6] J. Richeton, S. Ahzi, K. Vecchio, F. Jiang, and R. Adharapurapu, "Influence of temperature and strain rate on the mechanical behavior of tree amorphous polymers: characterization and modeling of the compressive yield stress," International Journal of Solids and Structures, vol. 43, no. 7-8, pp. 2318-2335, 2006.

[7] J. Mohanraj, D. Barton, I. Ward, A. Dahoun, J. Hiver, and C. G'Sell, "Plastic deformation and damage of polyoxymethylene in the large strain range at elevated temperatures," Polymer, vol. 47, no. 16, pp. 5852-5861, 2006.

[8] K. Cao, Y. Wang, and Y. Wang, "Effects of strain rate and temperature on the tension behayior of polycarbonate," Materials and Design, vol. 38, pp. 53-58, 2012.

[9] L. Zhang, X. Yao, S. Zang, and Q. Han, "Temperature and strain rate dependent tensile behavior of a transparent polyurethane interlayer," Materials and Design, vol. 65, pp. 1181-1188, 2015.

[10] I. Ward and J. Sweeney, Mechanical Properties of Solid Polymers, Wiley, Hoboken, NJ, USA, 3rd edition, 2013.

[11] A. Shaban, R. Mahnken, L. Wilke, H. Potente, and H. Ridder, "Simulation of rate dependent plasticity for polymers wit asymmetric effects," International Journal of Solids and Structures, vol. 44, no. 18-19, pp. 6148-6162, 2007.

[12] G. B. McKenna and L. J. Zapas, "Nonlinear viscoelastic behavior of poly (methyl methacrylate) in torsion," Journal of Rheology, vol. 23, no. 2, pp. 151-166, 1979.

[13] A. L. Flory and G. B. McKenna, "Chemical structure - normal force relationships in polymer glasses," Polymer, vol. 46, no. 14, pp. 5211-5217, 2005.

[14] W. Knauss and W. Zhu, "Nonlinearly viscoelastic behavior of polycarbonate. I. Response under pure shear," Mechanics of Time-Dependent Materials, vol. 6, no. 3, pp. 231-269, 2002.

[15] W. Knauss and W. Zhu, "Nonlinearly viscoelastic behavior of polycarbonate. II. The role of volumetric strain," Mechanics of Time-Dependent Materials, vol. 6, no. 4, pp. 301-322, 2002.

[16] K. Ravi-Chandar and Z. Ma, "Confined compression: a stable homogeneous deformation for constitutive characterization," Experimental Mechanics, vol. 40, no. 1, pp. 38-45, 2000.

[17] K. Ravi-Chandar and Z. Ma, "Inelastic deformation in polymers under multiaxial compression," Mechanics of TimeDependent Materials, vol. 4, no. 4, pp. 333-357, 2000.

[18] L. Zapas, "Nonlinear behavior of polyisobutylene solutions," in Deformation and Fracture of High Polymers, H. Henning Kausch, J. A. Hassell, and R. I. Jaffee, Eds., pp. 381-395, 1973.

[19] D. C. Venerus and H. Kahvand, "Doi-Edwards theory evaluation in double-step strain flows," Journal of Polymer Science. Part B. Polymer Physics, vol. 32, no. 8, pp. 1531-1542, 1994.

[20] D. C. Venerus, E. F. Brown, and W. R. Burghardt, "The nonlinear response of a polydisperse polymer solution to step strain deformations," Macromolecules, vol. 31, no. 26, pp. 9206-9212, 1998. 
[21] B. Bernstein, E. A. Kearsley, and L. J. Zapas, "A study of stress relaxation with finite strain," Transactions of the Society of Rheology, vol. 7, no. 1, pp. 391-410, 1963.

[22] D. Tscharnuter, M. Jerabek, Z. Major, and R. W. Lang, "Timedependent Poisson's ratio of polypropylene compounds for various strain histories," Mechanics of Time-Dependent Materials, vol. 15, no. 1, pp. 15-28, 2011.

[23] S. Pandini and A. Pegoretti, "Time and temperature effects on Poisson's ratio of poly(butylene terephthalate)," Express Polymer Letters, vol. 5, no. 8, pp. 685-697, 2011.

[24] S. Pandini and A. Pegoretti, "Time, temperature, and strain effects on viscoelastic Poisson's ratio of epoxy resins," Polymer Engineering and Science, vol. 48, no. 7, pp. 1434-1441, 2008.

[25] N. W. Tschoegl, W. G. Knauss, and I. Emri, "Poisson's ratio in linear viscoelasticity-a critical review," Mechanics of TimeDependent Materials, vol. 6, no. 1, pp. 3-51, 2002.

[26] P. Mallon, D. McCammond, and P. Benham, "Strain ratio and volume change during tension and compression creep of thermpoplastics," Polymer Engineering and Science, vol. 12, no. 6, pp. 420-424, 1972.

[27] ASTM D638-14, “ASTM compass,” August 2016, https:// compass.astm.org/download/D638.39258.pdf.

[28] ASTM D695-15, “ASTM compass," August 2016, https:// compass.astm.org/download/D695.3083.pdf.

[29] G. Odergard and A. Bandyopadhyay, "Physical aging of epoxy polymers and their composites," Journal of Polymer Science Part B: Polymer Physics, vol. 49, no. 24, pp. 1695-1716, 2011.

[30] D. A. Skoog, F. J. Holler, and S. R. Crouch, Principios de Análisis Instrumental, Cengage Learning Editores, Mexico D. F., Mexico, 6th edition, 2008.

[31] G. B. McKenna, "Mechanical rejuvenation in polymer glasses: fact or fallacy?," Journal of Physics: Condensed Matter, vol. 15, no. 11, pp. 737-763, 2003.

[32] L. C. E. Struik, Physical Aging in Amorphous Polymers and Other Materials, 1977.

[33] M. J. Mindel and N. Brown, "Creep and recovery of polycarbonate," Journal of Materials Science, vol. 8, no. 6, pp. 863-870, 1973.

[34] S. Jazouli, W. Luo, F. Brémand, and T. Vu-Khanh, "Nonlinear creep behavior of viscoelastic polycarbonate," Journal of Materials Science, vol. 41, no. 2, pp. 531-536, 2006.

[35] D. Colucci, P. O'Connell, and G. McKenna, "Stress relaxation experiments in polycarbonate: a comparison of volume changes for two commercial grades," Polymer Engineering and Science, vol. 37, no. 9, pp. 1469-1474, 1997.

[36] J. M. Caruthers, D. B. Adolf, R. S. Chambers, and P. Shrikhande, "A thermodynamically consistent, nonlinear viscoelastic approach for modeling glassy polymers," Polymer, vol. 45, no. 13, pp. 4577-4597, 2004.

[37] M. L. Cerrada and G. B. McKenna, "Physical aging of amorphous PEN: isothermal, isochronal and isostructural results," Macromolecules, vol. 33, no. 8, pp. 3065-3076, 2000. 


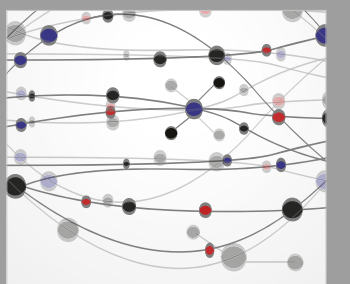

The Scientific World Journal
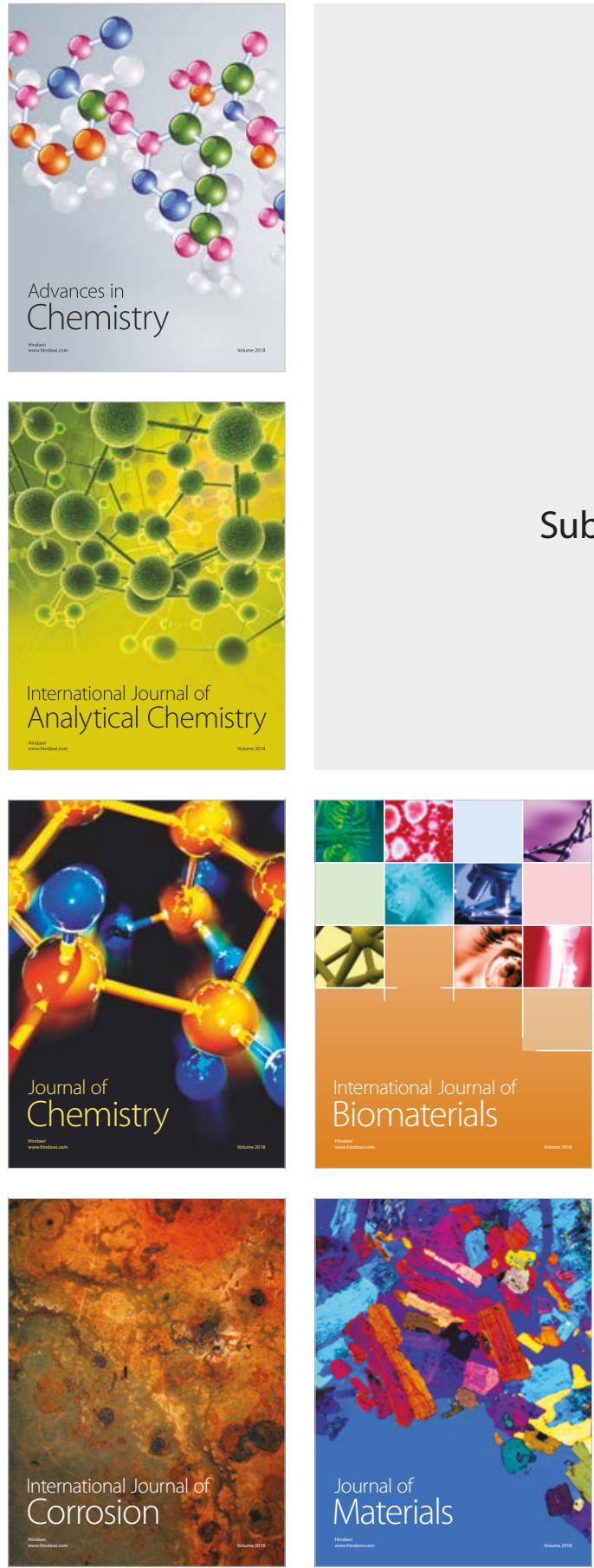

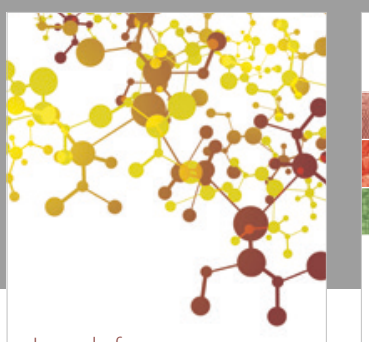

Journal of

Applied Chemistry
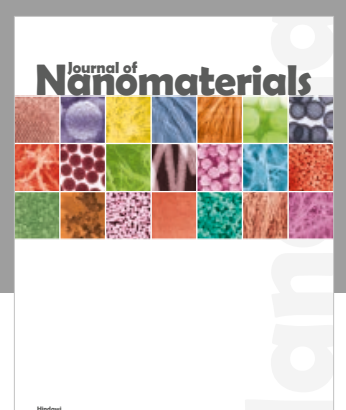

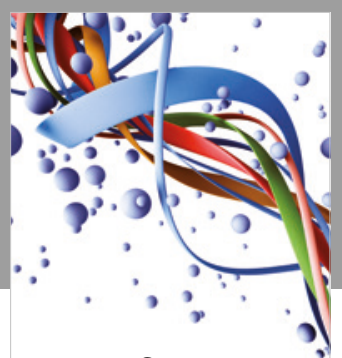

Scientifica

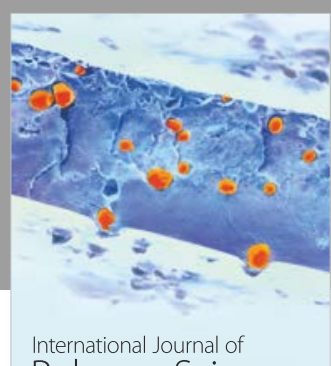

Polymer Science

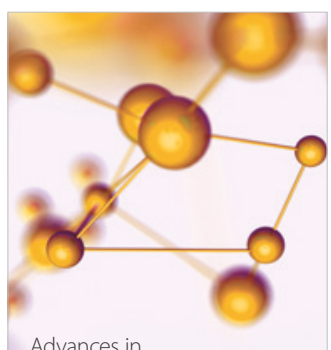

Physical Chemistry
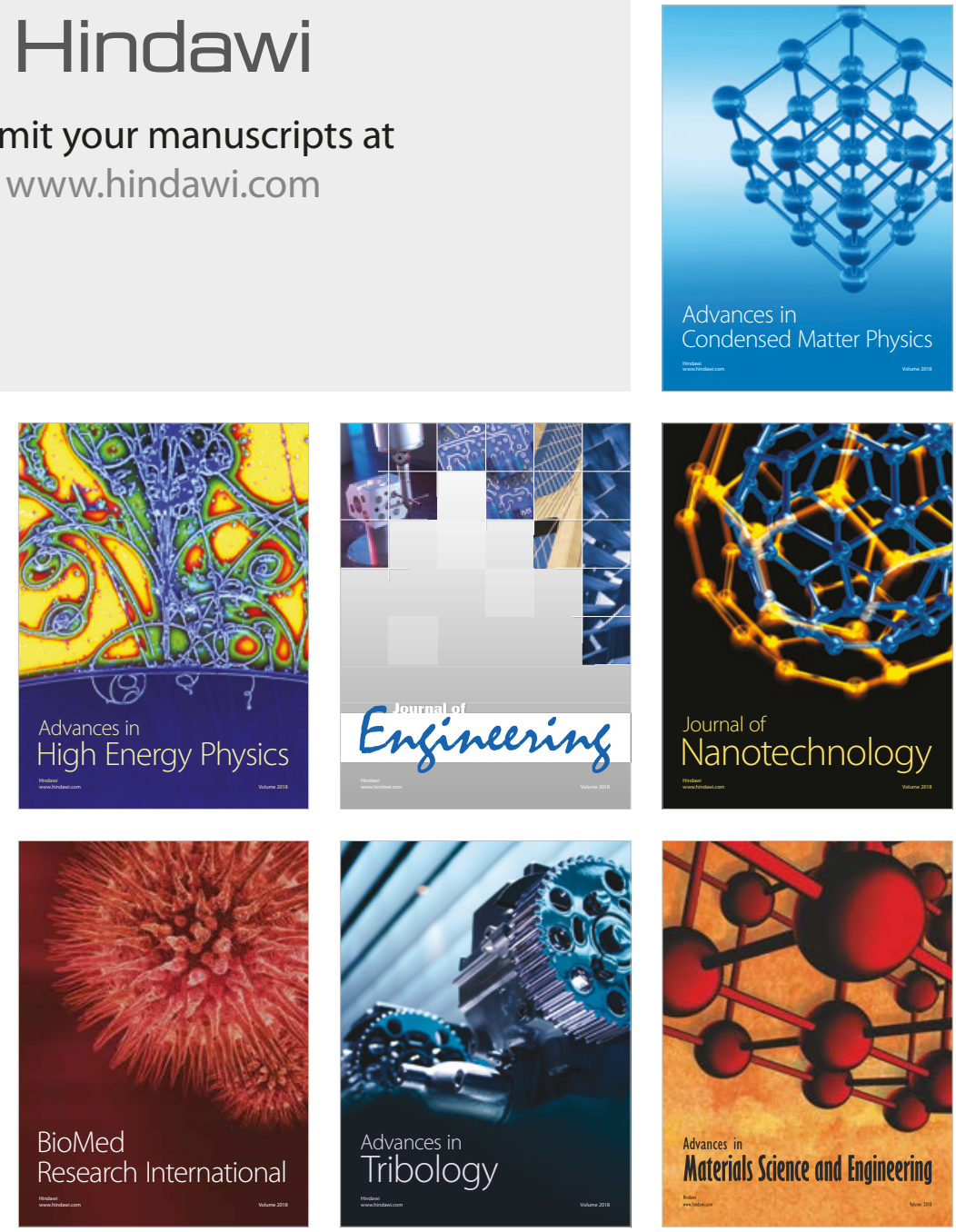